\title{
Investigation of the 0pposite Capacities of Erythropoietin and U-74389G on Platelet Crit Levels
}

\author{
C Tsompos ${ }^{1 *}$, C Panoulis ${ }^{2}$, K Toutouzas ${ }^{3}$, A Triantafyllou ${ }^{4}$, G Zografos ${ }^{5}$ and A Papalois ${ }^{6}$ \\ ${ }^{1}$ Department of Obstetrics \& Gynecology, Mesologi County Hospital, Greece \\ ${ }^{2}$ Department of Obstetrics \& Gynecology, Aretaieion Hospital, Athens University, Greece \\ ${ }^{3}$ Department of Surgery, Ippokrateion General Hospital, Athens University, Greece \\ ${ }^{4}$ Department of Biologic Chemistry, Athens University, Greece \\ ${ }^{5}$ Department of Surgery, Ippokrateion General Hospital, Athens University, Greece \\ ${ }^{6}$ Experimental Research Centre ELPEN Pharmaceuticals, Greece
}

*Corresponding author: Tsompos Constantinos, Department of Obstetrics \& Gynaecology, Mesologi County Hospital, Nafpaktou street, Mesologi 30200, Etoloakarnania, Greece

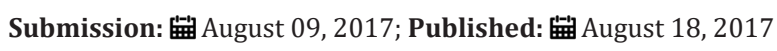
Abstract
Aim: This study calculated the opposite capacities of 2 drugs: the erythropoietin (Epo) and the antioxidant drug U-74389G. The calculation was
based on the results of 2 preliminary studies, each one of which estimated the platelet crit (PCT) levels alterations, after the respective drug usage in an
induced hypoxia reoxygenation animal experiment.

Materials and methods: The 2 main experimental endpoints at which the PCT levels (PCTl) were evaluated were the 60th reoxygenation min (for the groups A, C and E) and the 120th reoxygenation min (for the groups B, D and F). Specially, the groups A and B were processed without drugs, groups $\mathrm{C}$ and D after Epo administration; whereas groups $\mathrm{E}$ and $\mathrm{F}$ after U-74389G administration.

Results: The first preliminary study of Epo non significantly decreased the PCTl by $6.88 \% \pm 3.69 \%$ (p-value=0.0615). Also, the second preliminary study of U-74389 G non-significantly increased the PCTl by $6.73 \% \pm 37.45 \%$ (p-value $=0.0712$ ). These 2 studies were co-evaluated since they came from the same experimental setting. The outcome of the co-evaluation was that $U-74389 \mathrm{G}$ has opposite acute effect than Epo (p-value=0.0000).

Conclusion: The anti-oxidant capacities of U-74389G enhance the acute increasing properties on PCTl than epo (p-value=0.0000).

Keywords: Hypoxia; Erythropoietin; U-74389G; Platelet crit; Reoxygenation

\section{Introduction}

$\mathrm{U}-74389 \mathrm{G}$ is not famous for its increasing [1] capacity (p-value $=0.0712$ ).U-74389G as a novel antioxidant factor, implicates exactly only 255 published studies. The hypoxia reoxygenation (HR) type of experiments was noted in $4.31 \%$ of these studies. A tissue protective feature of U-74389G was obvious in these HR studies. The U-74389G chemically known as 21-[4-(2,6-di-1-pyrrolidinyl4-pyrimidinyl)-1-piperazinyl]-pregna-1,4,9(11)-triene-3,20-dione maleate salt is an antioxidant complex, which prevents the lipid peroxidation either iron-dependent, or arachidonic acid-induced one. Animal kidney, liver, brain microvascular endothelial cells monolayers and heart models were protected by U-74389G after HR injury. U-74389G also attenuates the leukocytes; downregulates the proinflammatory gene; treats the endotoxin shock; produces cytokine; enhances the mononuclear immunity; protects the endothelium and presents antishock property.
Erythropoietin (Epo) even if is notfamous for its acute decreasing action ( $p$-value $=0.0615$ ), it can be used as a reference drug in order a related capacity of U-74389G to become comprehensible. Although Epo is met in over 29,645 published biomedical studies, only a $10.48 \%$ of them negotiate the known type of HR experiments. Nevertheless, Epo as a cytokine, never goes out of the jurisdiction of the PCTl study. This experimental work tried to compare the kind of effects of the above drugs on a rat induced HR protocol. They were tested by calculating the serum PCTl alterations.

\section{Materials and Methods}

\section{Animal preparation}

The Vet licenses under 3693/12-11-2010 \& 14/10-1-2012 numbers, the granting company and the experiment location are mentioned in preliminary references [1,2]. The human animal 
care of Albino female Wistar rats, the 7 days pre-experimental ad libitum diet, the non-stop intra-experimental anaesthesiology techniques, the acidometry, the electrocardiogram and the oxygen supply and post-experimental euthanasia are also described in preliminary references. Rats were $16-18$ weeks old. They were randomly assigned to six 6 groups consisted in $\mathrm{N}=10$. The stage of $45 \mathrm{~min}$ hypoxia was common for all 6 groups. Afterwards, reoxygenation of $60 \mathrm{~min}$ was followed in group A; reoxygenation of 120 min in group B; immediate Epo intravenous (IV) administration and reoxygenation of $60 \mathrm{~min}$ in group C; immediate Epo IV administration and reoxygenation of $120 \mathrm{~min}$ in group $\mathrm{D}$; immediate U-74389G IV administration and reoxygenation of 60min in group E; and immediate U-74389G IV administration and reoxygenation of $120 \mathrm{~min}$ in group $\mathrm{F}$. The dose height assessments for both drugs are described at preliminary studies as $10 \mathrm{mg} / \mathrm{Kg}$ body mass.

Hypoxia was caused by laparotomic clamping the inferior aorta over renal arteries by forceps for $45 \mathrm{~min}$. The clamp removal was restoring the inferior aorta patency and reoxygenation. After exclusion of the blood flow, the protocol of HR was applied, as described above for each experimental group. The drugs were administered at the time of reperfusion; through inferior vena cava catheter. The PCT levels (PCTl) were determined at 60th min of reoxygenation (for A, C and E groups) and at 120th min of reoxygenation (for B, D and F groups). No relation was found between PCTl with animal's mass ( $p$-value=0.5401).

\section{Statistical analysis}

Table 1 presents the (\%) declining influence of Epo regarding reoxygenation time. Also, Table 2 presents the (\%) increasing influence of U-74389G regarding reoxygenation time. Chi-square tests were applied using the ratios which produced the (\%) results per endpoint. The outcomes of chi-square tests are depicted at (Table 3). The statistical analysis was performed by Stata 6.0 software [Stata 6.0, Stata Corp LP, Texas, USA].

Table 1: The (\%) declining influence of erythropoietin in connection with reoxygenation time.

\begin{tabular}{|c|c|c|c|}
\hline Decrease & $\mathbf{\pm S D}$ & Reoxygenation Time & p-Value \\
\hline$-16.47 \%$ & $\pm 26.13 \%$ & $1 \mathrm{~h}$ & 0.0921 \\
\hline$-13.74 \%$ & $\pm 21.07 \%$ & $1.5 \mathrm{~h}$ & 0.0158 \\
\hline$-11.01 \%$ & $\pm 15.50 \%$ & $2 \mathrm{~h}$ & 0.0882 \\
\hline$+0.67 \%$ & $\pm 24.05 \%$ & reperfusion time & 0.9083 \\
\hline$-6.88 \%$ & $\pm 3.69 \%$ & interaction & 0.0615 \\
\hline
\end{tabular}

Table 2: The (\%) increasing influence of U-74389G in connection with reoxygenation time.

\begin{tabular}{|c|c|c|c|}
\hline Increase & $\mathbf{\pm S D}$ & Reoxygenation Time & $\mathbf{p}$-Values \\
\hline$+3.80 \%$ & $\pm 21.58 \%$ & $1 \mathrm{~h}$ & 0.6373 \\
\hline$+9.23 \%$ & $\pm 21.89 \%$ & $1.5 \mathrm{~h}$ & 0.1064 \\
\hline$+14.66 \%$ & $\pm 22.31 \%$ & $2 \mathrm{~h}$ & 0.0833 \\
\hline$+3.76 \%$ & $\pm 20.02 \%$ & reperfusion time & 0.4803 \\
\hline$+6.73 \%$ & $\pm 37.45 \%$ & interaction & 0.0712 \\
\hline
\end{tabular}

Table 3: The U-74389G/erythropoietin efficacies ratios on PCTl after chi-square tests application.

\begin{tabular}{|c|c|c|c|c|}
\hline Odds Ratio & \multicolumn{2}{|c|}{$[95 \%$ Conf. Interval] } & p-Values & Endpoint \\
\hline-0.2312044 & -.2667818 & -.200372 & 0.0000 & $1 \mathrm{~h}$ \\
\hline-0.6719365 & -.6726743 & -.6711995 & 0.0000 & $1.5 \mathrm{~h}$ \\
\hline-1.330756 & -1.848376 & -.9580512 & 0.0886 & $2 \mathrm{~h}$ \\
\hline 5.620077 & 5.601274 & 5.638943 & 0.0000 & $\begin{array}{c}\text { Reperfusion } \\
\text { time }\end{array}$ \\
\hline-0.9771515 & -.9784991 & -.9758057 & 0.0000 & Interaction \\
\hline
\end{tabular}

\section{Results}

The successive application of chi-square tests revealed that U-74389G accentuated the PCTl by -.2312044 -fold [-.2667818 - -.200372] than Epo at 1h, by -.6719365-fold [-.6726743 $-.6711995]$ at $1.5 \mathrm{~h}$, by -1.330756 -fold [-1.848376 - -.9580512] at $2 \mathrm{~h}$, by 5.620077 -fold [5.601274 - 5.638943] without drugs and by -.9771515-fold [-.9784991 - -.9758057] whether all variables have been considered ( $\mathrm{p}$-value $=0.0000)$.

\section{Discussion}

The unique available study investigating the increasing effect of U-74389G on PCTl was the preliminary one [1]. Although the most famous activities of neuroprotection and membrane-stabilization properties, it accumulates in the cell membrane, protecting vascular endothelium from peroxidative damage but hardly penetrates the blood-brain barrier. It elicits a beneficial effect in ototoxicity and Duchenne muscular dystrophy. It increases $\gamma \mathrm{GT}$, SOD, and GSH levels in oxygen-exposed cells. It treats septic states and acts as immunosuppressant in flap survival. It prevents the learning impairments, it delays the early synaptic transmission decay during hypoxia improving energetic state of neurons. It shows antiproliferative properties on brain cancer cells and is considered as a new promising anti inflammatory drug for the treatment of reperfusion syndrome in IR injuries.

The same authors confirmed [2] the short-term declining effect of Epo preparations in non iron deficient rats. Rajajee et al. [3] considered acute liver failure patients typically coagulopathic and at risk for intracranial hemorrhage. Fealy et al. [4] associated the decreased platelet count (hazards ratio, 1.19; $\mathrm{p}=0.03$ ) with a reduced likelihood of circuit clotting repeated events in critically ill adults requiring continuous renal replacement therapy. Muzaffar et al. [5] could differentiate among normo coagulant, hypo coagulant, hyper coagulant states by thromboelastography unlike conventional coagulation assay which estimated the platelet count at $153.96 \pm 99.16\left(\times 10^{3} / \mathrm{mm}^{3}\right)$. Htet et al. [6] estimated almost $20 \%$ of critically ill patients having moderate-to-severe coagulopathy (platelets $<50 \mathrm{k} / \mathrm{uL}$ ). Shaver et al. [7] associated the elevated micro particle (MP) concentrations in the airspace during ARDS with activation of coagulation, reduced risk of ARDS and contribute to acute lung injury in critically ill patients. Etchill et al. [8] associated 
the high platelets-to-packed RBCs ratio ( $>1: 2)$ with decreased 48hour mortality $54.4 \%(p=0.032)$ in trauma patients. Mundt et al. [9] showed that differences in platelet counts are not formaldehyde exposure dependent since it induces damage to hematopoietic cells. Francischetti et al. [10] found that post-cannulation platelet counts among other variables also have discriminative power within 30 days in surviving patients on ECMO. Jones et al. [11] claimed that packed platelets break down and undergo chemical changes during storage (known as the storage lesion) that lead to an inflammatory response once the blood components are transfused to patients deteriorating their outcome. Bruchim et al. [12] significantly (P $<0.05$ ) associated the haemostatic derangements of lower tPCA at 12 hours post presentation with the $60 \%$ mortality in dogs with naturally occurring heatstroke. Pannu et al. [13] reversed rapidly and safely severe thrombocytopenia $\left(\leq 20,000 / \mathrm{mm}^{3}\right)$ secondary to dengue virus (DEV) infection by administration of a single dose of $50 \mu \mathrm{g} / \mathrm{kg}(25 \mathrm{IU} / \mathrm{kg})$ anti-D IV. Patients in the intervention group were achieving 9.85-fold more frequently the platelet count of $\geq 50,000 / \mathrm{mm} 3$ than control group $(P=0.0019)$ at the end of $48 \mathrm{~h}$. Mohammed et al. [14] significantly increased PLTs intracellular ascorbic acid levels by 2.66-fold (Lo Vitamin C) and by 13.08-fold (Hi Vitamin $\mathrm{C}, \mathrm{P}<0.05)$ after Vitamin $\mathrm{C}$ supplementation. Also, Vitamin $\mathrm{C}$ at the higher dose ( $3 \mathrm{mmol} / \mathrm{L})$ also induced the release of several eicosanoids including thromboxane $\mathrm{B}_{2}$ and prostaglandin $\mathrm{E}_{2}$, as well as products of arachidonic acid metabolism via the lipoxygenases pathway such as 11-/12-/15-hydroxyicosatetraenoic acid ( $\mathrm{P}<0.05)$. Marly Voquer et al. [15] ascribed the stronger clot in the FIBTEM assay of rotational thromboelastometry at a stronger contribution of platelets in feline blood of people than cats. Aubron et al. [16] independently associated platelet transfusion with 5.5-fold more hospital-acquired infections in the ICU $(p<0.01)$, with $2.56 \%$-fold more infections $(\mathrm{p}<0.001)$. Navas Carrillo et al. [17] described the formation of luminal thrombi secondary to platelet activation and the release of thrombogenic elements within the atherosclerotic lesions in acute coronary syndromes. Appiah Kubi et al. [18] detected 36 oncogenic platelet-derived growth factor receptor (PDGFR) ETV6 (TEL)-PDGFRB and FIP1L1PDGFRA fusions genes. 33 were as a result of chromosomal translocation, FIP1L1-PDGFRA and EBF1-PDGFRB were the result of chromosomal deletion and CDK5RAP2- PDGFRA was the result of chromosomal insertion in hematological malignancies. Asanuma et al. [19] estimated the mean values of PCT significantly lower and the TPO levels significantly higher in hemodialysis patients (HD) patients undergoing treatment with rHuEPO at $9000 \mathrm{IU} /$ week than those in healthy controls. Haddad et al. [20] examined the effect of intra peritoneal injections of $40 \mathrm{mg} / \mathrm{kg}$ of the U-74389G every 12 hours, on acute otitis media in guinea pigs. Streptococcus pneumonia organisms were inoculated into the right tympanic cavity; with the left ear served as a control one. According to above, Table 3 shows that U-74389G accentuated by -.9771515fold [-.9784991 - -.9758057] the PCTl than Epo (p-value=0.0000); a trend accentuated along time, in Epo non-deficient rats. A metaanalysis of these ratios from the same experiment, for 4 other seric variables, provides comparable results (Table 4).

Table 4: A U-74389G / erythropoietin efficacies ratios meta-analysis on 4 hematologic variables (3 variables with balancing efficacies and 1 variable with opposite efficacies) [21].

\begin{tabular}{|c|c|c|c|c|c|c|c|c|c|c|}
\hline \begin{tabular}{c} 
Endpoint \} $\\
{\text { Variable }}$ & $1 \mathrm{~h}$ & p-Value & $1.5 \mathrm{~h}$ & p-Value & $2 \mathrm{~h}$ & p-Value & $\begin{array}{l}\text { Reperfusion } \\
\text { Time }\end{array}$ & p-Value & Interaction & p-Value \\
\hline Hematocrit & 38.424 & 0 & 9.076658 & 0 & 6.222898 & 0 & 1.001356 & 0.2184 & 12.66419 & 0 \\
\hline Haemoglobin & 1.268689 & 0 & 1.839035 & 0 & 13.1658 & 0 & 1.252422 & 0 & 1.94889 & 0 \\
\hline Creatinine & 168.9034 & 0 & 4.872332 & 0 & 3.039572 & 0 & 1.0262016 & 0 & 5.005523 & 0 \\
\hline Mean & 20.1929009 & 0 & 4.33262345 & 0 & 6.29145057 & 0 & 1.08773713 & 0.0728 & 4.98048231 & 0 \\
\hline
\end{tabular}
\end{tabular}

\begin{tabular}{|c|c|c|c|c|c|c|c|c|c|c|}
\hline $\begin{array}{l}\text { Endpoint } \\
\text { Variable }\end{array}$ & $1 \mathrm{~h}$ & p-Value & $1.5 \mathrm{~h}$ & p-Value & $2 h$ & p-Value & $\begin{array}{l}\text { Reperfusion } \\
\text { Time }\end{array}$ & p-Value & Interaction & p-Value \\
\hline $\begin{array}{c}\text { Mean } \\
\text { corpuscular } \\
\text { haemoglobin } \\
\text { concentrations }\end{array}$ & -0.2774225 & 0 & -0.55047 & 0 & -0.85224 & 0 & +3.044774 & 0 & -0.7793243 & 0 \\
\hline
\end{tabular}

\section{Conclusion}

The anti-oxidant capacities of U-74389G accentuated by -.9771515-fold [-.9784991 - -.9758057] the PCTl than Epo ( $\mathrm{p}$-value $=0.0000$ ) in rats. Also, this trend is accentuated along the short term time frame of the experiment.

\section{References}

1. Tsompos C, Panoulis C, Toutouzas K, Zografos G, Papalois A (2015) The acute effect of the antioxidant drug "U-74389G" on platelet crit levels during hypoxia reoxygenation injury in rats. Acta Phlebologica 16(2): 77-81.

2. Tsompos C, Panoulis C, Toutouzas K, G Zografos, Papalois A (2013) The effect of erythropoietin on platelet crit during ischemia reperfusion injury in rats. Annals of the Romanian Society for cell Biology 18(2): 3942.

3. Rajajee V, Fontana RJ, Courey AJ, Patil PG (2017) Protocol based invasive intracranial pressure monitoring in acute liver failure: feasibility, safety and impact on management. Crit Care 21(1): 178.

4. Fealy N, Aitken L, du Toit E, Lo S, Baldwin I (2017) Faster Blood Flow Rate Does Not Improve Circuit Life in Continuous Renal Replacement Therapy: A Randomized Controlled Trial. Crit Care Med.

5. Muzaffar SN, Baronia AK, Azim A, Verma A, Gurjar M, et al. (2017) Thromboelastography for Evaluation of Coagulopathy in Nonbleeding Patients with Sepsis at Intensive Care Unit Admission. Indian J Crit Care Med 21(5): 268-273.

6. Htet N, Vaughn J, Adigopula S, Hennessey E, Mihm F (2017) Needleguided ultrasound technique for axillary artery catheter placement in 
critically ill patients: A case series and technique description. J Crit Care 41: 194-197.

7. Shaver CM, Woods J, Clune JK, Grove BS, Wickersham NE, et al. (2017) Circulating microparticle levels are reduced in patients with ARDS. Crit Care 21(1): 120.

8. Etchill EW, Myers SP, McDaniel LM, Rosengart MR, Raval JS, et al. (2017) Should All Massively Transfused Patients Be Treated Equally? An Analysis of Massive Transfusion Ratios in the Nontrauma Setting. Crit Care Med 45(8): 1311-1316.

9. Mundt KA, Gallagher AE, Dell LD, Natelson EA, Boffetta P, et al. (2017) Does occupational exposure to formaldehyde cause hematotoxicity and leukemia-specific chromosome changes in cultured myeloid progenitor cells? Crit Rev Toxicol 47(7): 592-602.

10. Francischetti IMB, Szymanski J, Rodriguez D, Heo M, Wolgast LR (2017) Laboratory and clinical predictors of 30-day survival for patients on Extracorporeal Membrane Oxygenation (ECMO): 8-Year experience at Albert Einstein College of Medicine, Montefiore Medical Center. J Crit Care 40: 136-144.

11.Jones AR, Frazier SK (2017) Consequences of Transfusing Blood Components in Patients With Trauma: A Conceptual Model. Crit Care Nurse 37(2): 18-30.

12. Bruchim Y, Kelmer E, Cohen A, Codner C, Segev G, et al. (2017) Haemostatic abnormalities in dogs with naturally occurring heatstroke. J Vet Emerg Crit Care (San Antonio) 27(3): 315-324.

13. Pannu AK, Bhalla A, Singhal M, Suri V, Shafiq N, et al. (2017) Safety and Efficacy of a Single Dose of Anti-D (WinRho®) in Severe Thrombocytopenia Secondary to Dengue Virus Infection. Indian J Crit Care Med 21(2): 80-84.
14. Mohammed BM, Sanford KW, Fisher BJ, Martin EJ, Contaifer D, et al. (2017) Impact of high dose vitamin C on platelet function. World J Crit Care Med 6(1): 37-47.

15. Marly Voquer C, Riond B, Jud Schefer R, Kutter AP (2017) Reference values for rotational thromboelastometry (ROTEM) in clinically healthy cats. J Vet Emerg Crit Care (San Antonio). 27(2): 185-192.

16. Aubron C, Flint AW, Bailey M, Pilcher D, Cheng AC, et al. (2017) Is platelet transfusion associated with hospital-acquired infections in critically ill patients? Crit Care 21(1): 2.

17. Navas Carrillo D, Marín F, Valdés M, Orenes Piñero E (2017) Deciphering acute coronary syndrome biomarkers: High-resolution proteomics in platelets, thrombi and microparticles. Crit Rev Clin Lab Sci 54(1): 49-58.

18.Appiah Kubi K, Lan T, Wang Y, Qian H, Wu M, et al. (2017) Plateletderived growth factor receptors (PDGFRs) fusion genes involvement in hematological malignancies. Crit Rev Oncol Hematol 109: 20-34.

19. Asanuma M, Seino K, Mizuno T, Nasu M, Yamauchi F, et al. (2010) Plasma thrombopoietin level and platelet indices in hemodialysis patients receiving recombinant human erythropoietin. Int J Lab Hematol 32(3): 312-319.

20.Haddad J, Egusa K, Takoudes TG (1998) Effects of 21-aminosteroid U-74389G on acute otitis media in a guinea pig model. Otolaryngol Head Neck Surg 118(1): 44-48.

21.Tsompos C, Panoulis C, Toutouzas K, Triantafyllou A, Zografos G, et al. (2017) Comparison of the acute chromic capacities of erythropoietin and U-74389G concerning mean corpuscular hemoglobin concentration levels. Discovery 53(260): 443-447. 